\title{
Design and Psychometric Analysis of the COVID-19 Prevention, Recognition and Home-Management Self-Efficacy Scale
}

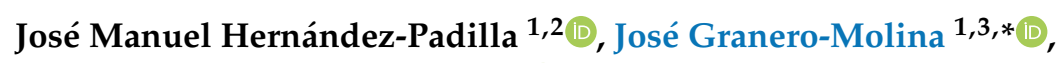 \\ María Dolores Ruiz-Fernández ${ }^{1}$ (D) , Iria Dobarrio-Sanz ${ }^{1}$, María Mar López-Rodríguez ${ }^{1}$, \\ Isabel María Fernández-Medina ${ }^{1}\left(\mathbb{D}\right.$, Matías Correa-Casado ${ }^{1,4}$ and Cayetano Fernández-Sola ${ }^{1,3}(\mathbb{D})$ \\ 1 Nursing Science, Physiotherapy and Medicine Department, Faculty of Health Sciences, University of \\ Almeria, 04120 Almería, Spain; j.hernandez-padilla@ual.es (J.M.H.-P.); mrf757@ual.es (M.D.R.-F.); \\ ids135@ual.es (I.D.-S.); mlr295@ual.es (M.M.L.-R.); Isabel_medina@ual.es (I.M.F.-M.); \\ mcc249@ual.es (M.C.-C.); cfernan@ual.es (C.F.-S.) \\ 2 Adult, Child and Midwifery Department, School of Health and Education, Middlesex University, \\ London NW4 4BT, UK \\ 3 Associate Researcher, Faculty of Health Sciences, Universidad Autónoma de Chile, Temuco 4780000, Chile \\ 4 Clinical Manager, Internal Medicine Ward (COVID-19 area), Hospital de Poniente, 04700 Almería, Spain \\ * Correspondence: jgranero@ual.es
}

Received: 20 May 2020; Accepted: 24 June 2020; Published: 28 June 2020

\begin{abstract}
In order to control the spread of COVID-19, people must adopt preventive behaviours that can affect their day-to-day life. People's self-efficacy to adopt preventive behaviours to avoid COVID-19 contagion and spread should be studied. The aim of this study was to develop and psychometrically test the COVID-19 prevention, detection, and home-management self-efficacy scale (COVID-19-SES). We conducted an observational cross-sectional study. Six-hundred and seventy-eight people participated in the study. Data were collected between March and May 2020. The COVID-19-SES' validity (content, criterion, and construct), reliability (internal consistency and test-retest reliability), and legibility were studied. The COVID-19-SES' reliability was high (Cronbach's alpha $=0.906$; intraclass correlation coefficient $=0.754)$. The COVID-19-SES showed good content validity (scale's content validity index $=0.92$ ) and good criterion validity when the participants' results on the COVID-19-SES were compared to their general self-efficacy $(r=0.38 ; p<0.001)$. Construct validity analysis revealed that the COVID-19-SES' three-factor structure explained 52.12\% of the variance found and it was congruent with the World Health Organisation's recommendations to prevent COVID-19 contagion and spread. Legibility analysis showed that the COVID-19-SES is easy to read and understand by laypeople. The COVID-19-SES is a psychometrically robust instrument that allows for a valid and reliable assessment of people's self-efficacy in preventing, detecting symptoms, and home-managing COVID-19.
\end{abstract}

Keywords: COVID-19; psychometrics; self-efficacy

\section{Introduction}

The coronavirus disease (COVID-19) pandemic has caused a public health emergency worldwide [1]. COVID-19 is a potentially fatal disease caused by the severe acute respiratory syndrome coronavirus 2 (SARS-CoV-2) [1-3]. The clinical presentation of COVID-19 can vary widely. Whilst most patients seem to remain asymptomatic or present with mild to moderate upper respiratory tract illness $[4,5]$, some develop severe viral pneumonia with respiratory failure that can lead to death $[1-3,6]$. According to initial reports, many people with COVID-19 require hospitalisation or 
critical care [3,5,7-9]. Consequently, many countries have implemented strict public health measures to contain the spread of COVID-19 [10]. All these public health measures rely on the general public's ability to adopt protective behaviours to avoid the contagion and spread of COVID-19 (for example, hand hygiene and social distancing) $[10,11]$. Since some of these public health measures are considered disruptive to people's day-to-day life [12], their behavioural responses should be studied. However, little is known about people's behavioural response to adopt all the recommended protective behaviours amidst the COVID-19 pandemic.

\section{Background}

Available evidence suggests that COVID-19 is a highly transmittable disease [13-15]. It is estimated that one case of COVID-19 could cause between 3 and 6 secondary cases during the outbreak [15]. In addition, early reports indicate that $7-16 \%$ of all COVID-19 cases may need hospitalisation and $5-12 \%$ could need ICU admission [3,5,7-9]. As evidence suggests that critical care capacities could be exceeded due to the COVID-19 pandemic $[16,17]$, many governments worldwide have prioritised public health measures to control the spread of COVID-19 and flatten the peak of morbidity and mortality caused by the pandemic $[10,18,19]$. Following the World Health Organisation's (WHO) advice [11,20], governments have urged the general public to implement protective behaviours to avoid the contagion and spread COVID-19 $[10,18,19]$. Some of these recommendations require individuals to be able to maintain social distancing, identify COVID-19 symptoms, follow local protocols to seek healthcare advice, or even manage people with mild symptoms of COVID-19 at home under strict preventative measures to avoid the contagion and spread [11,20]. In addition, more waves of the COVID-19 pandemic are expected in the future [21,22], which may lead to having to adopt the above-mentioned protective behaviours for long periods of time. Therefore, healthcare professionals and behavioural scientists should study the general public's protective behavioural responses amidst the COVID-19 pandemic [19].

According to the protection motivation theory (PMT), self-efficacy is considered a robust predictor of various health-related behaviours [23,24]. Bandura's Social Cognitive Theory defines self-efficacy as one's perceived ability to perform a target behaviour $[25,26]$. Research has shown that self-efficacy could predict the general public's intention to engage in social distancing during a simulated pandemic caused by a respiratory infectious disease [24]. Furthermore, higher self-efficacy levels have been linked to taking other preventive measures during the SARS and influenza A pandemics (for example: handwashing, respiratory hygiene, and wearing a mask when having symptoms) [27-29]. In this regard, an individual's self-efficacy in preventing, recognising symptoms, and home-managing COVID-19 should be studied and analysed. Nevertheless, although numerous instruments to assess behavioural responses during an epidemic have been used [28,30,31], there are no validated tools that would allow for a valid and reliable assessment of individuals' self-efficacy in preventing, recognising symptoms, and home-managing a respiratory infectious disease. The aim of this study is to develop and psychometrically test the COVID-19 prevention, recognition, and home-management self-efficacy scale (COVID-19-SES).

\section{Materials and Methods}

\subsection{Design}

We completed the study in two phases following an observational cross-sectional design. In the first phase, we generated the tool's items and pilot tested its content validity and reliability (i.e., internal consistency and test-retest reliability). In the second phase, we assessed the COVID-19-SES' validity (i.e., content, criterion and construct validity), reliability (i.e., internal consistency and test-retest reliability), and legibility. 


\subsection{Participants and Sampling}

We used a convenience sampling method to recruit 678 participants. All participants had to be at least 18 years old and accept voluntary participation before taking part in the study. In line with expert guidelines [32-34], we recruited between 50-60 participants for the pilot study $(N=56)$ and more than 10 participants per item for the final validation study $(N=622)$. Individuals who participated in the pilot study did not take part in the final validation study.

\subsection{Data Collection}

We collected data between March and May 2020 through online surveying. We generated an online questionnaire with three different sections. In the first section, we asked the participants to provide some demographic information (i.e., age, gender, level of education completed, occupation, history of respiratory or cardiovascular chronic conditions, perceived health, and experience of COVID-19 symptoms). In the second section, we asked the participants to complete the COVID-19-SES. In the last section, we asked the participants to complete the General Self-Efficacy Scale (GSES) [35]. For the pilot study, the participants completed the same online questionnaire twice with a 2-week interval. In the final validation study, the participants were asked to complete the COVID-19-SES twice with a four-week interval. This allowed us to explore the COVID-19-SES test-retest reliability.

\subsection{Ethical Considerations}

The study was approved by the competent Ethics and Research Committee (protocol reference code: 76/2020). In the introductory section of the online survey, we provided information about the study (i.e., justification, aim, and methods), our research group, and participants' right to withdraw at any point. We also explained how we were going to safeguard their anonymity and confidentiality. All data were treated according to the European legislation on data protection. Only three members of the research team had access to the raw data generated by the online survey platform (M.D.R.-F., I.D.-S., and M.C.-C.). They were in charge of coupling the participants' test-retest responses and deleting the participants' emails from the initial database. Then, the complete initial database (without email addresses) was handed to two different researchers (I.M.F.-M, M.M.L.-R.), who transferred all the data into a SPSS database and randomised the order of the responses. Once the SPSS database was created, the participants' responses were deleted from the cloud and all the researchers' laptops. Only the principal researcher has access to the blind SPSS database used for data analysis. All participants accepted voluntary participation before completing the online questionnaire by ticking a box that stated, "I agree to participate in the study described above and give my consent for my responses to be used with research purposes."

\subsection{Phase 1: Item Generation and Pilot Study of the COVID-19-SES}

\subsubsection{Item Generation}

According to the PMT, both the effectiveness of recommended behaviours and one's self-efficacy to perform such behaviours strongly influence people's motivation to engage in health-preventive conducts $[23,24]$. In line with the PMT, we generated the COVID-19-SES' items based on the WHO's recommended behaviours to protect oneself and others from the spread of COVID-19 [11,20]. Firstly, the research team analysed all the WHO recommendations and identified three categories in which to group the items: (1) prevention of COVID-19 spread and contagion, (2) early recognition of COVID-19 symptoms, and (3) home-management of patients with (or suspected) COVID-19 [11,20]. Secondly, we summarised the WHO recommendations and created the initial 19-item version of the COVID-19-SES. The 19 items comprising the COVID-19-SES were created by consensus. Following Bandura's Social Cognitive Theory, people's self-efficacy to adopt protective behaviours was measured in terms of their own capabilities to perform such behaviours $[25,26]$. In line with Bandura's recommendations, the response options ranged from 0 ("completely sure that I cannot do it") to 100 ("completely sure 
that I can do it") $[25,36]$. In addition, we added some degree of difficulty to all the items in order to avoid a ceiling effect (for example: "in any context" at the end of item 4 and "even if my professional or social life are at stake" at the end of item 5) [37].

\subsubsection{Pilot Study Methods}

Before conducting a final validation study, we explored the COVID-19-SES' content validity using a panel of experts and then tested its reliability after administering it to a pilot sample $(N=56)$.

\section{Content Validity}

We followed Polit \& Beck's recommendations to explore the COVID-19-SES' content validity [32]. Firstly, we recruited a panel of 14 experts from 5 different institutions in Spain and the UK. All the experts were either physicians or nurses with more than 10 years' experience in public health, epidemiology, or infectious diseases. Secondly, we asked the experts to rate the 19 items comprising the COVID-19-SES depending on their relevance to measure people's self-efficacy in preventing, detecting symptoms, and home-managing COVID-19 ( 1 = not relevant; 2 = somewhat relevant; 3 = quite relevant; 4 = highly relevant) [31]. Lastly, we calculated each item's content validity index (i-CVI) by adding the number of experts who rated the item as "quite relevant" or "highly relevant" and dividing it by the total number of experts [32]. We considered that an i-CVI $\geq 0.78$ was appropriate [32].

\section{Reliability}

To pilot test the COVID-19-SES, we administered the questionnaire to 56 participants and explored the tool's internal consistency and test-retest reliability. We decided that an item positively contributed to the COVID-19-SES' internal consistency if its corrected item-total correlation index (C-ITC) was higher than 0.3 and the tool's Cronbach's alpha $(\alpha)$ did not increase significantly after removing that item [34]. Additionally, we computed the scale's $\alpha$ and considered this as appropriate if it was higher than 0.7 [32]. To explore the COVID-19-SES' test-retest reliability, we computed the intraclass correlation coefficient (ICC) between the participants' scores on the test and on the retest we performed two weeks later. An ICC > 0.5 was deemed as appropriate [32].

\subsection{Phase 2: Final Validity, Reliability, and Legibility Analysis of the COVID-19-SES}

Following Streiner \& Kottner's recommendations, we tested the COVID-19-SES' validity (i.e., content, criterion and construct) and reliability (i.e., internal consistency and test-retest reliability) [34]. Additionally, we explored the scale's legibility and developed an internal scoring system [32,38]. We analysed the data using IBM ${ }^{\circledR}$ SPSS Statistics ${ }^{\circledR}$ v.25 (IBM Company, Chicago, IL, USA). The COVID-19-SES was created and tested in Spanish. Four independent translators participated in the forward-backward procedure to translate the English version of the COVID-19-SES presented in this paper [39]. Two independent native English translators (proficient in Spanish) translated the COVID-19-SES from Spanish to English. The small differences between their translations were reconciled by consensus and a single English version of the COVID-19-SES was created. Two independent native Spanish translators (proficient in English) performed a backtranslation of the COVID-19-SES English version into Spanish. Again, small differences in their backtranslation were reconciled by consensus. The research team and the translators examined the original COVID-19-SES, its English translation, and the backtranslation in Spanish. It was unanimously considered that the English version of the COVID-19-SES included in this paper respected the semantics of the original tool. 


\subsubsection{Validity}

\section{Content Validity}

We explored the COVID-19-SES' content validity following the same method as the one described in phase 1. In addition, we calculated the scale's content validity index (S-CVI). We deemed appropriate a S-CVI higher than 0.78 [32].

\section{Criterion Validity}

In order to explore the instrument's criterion validity, we correlated the participants' results on the COVID-19-SES with their results on the General Self-Efficacy Scale (GSES) [35]. Prior to this, we performed a normality test on the variable "mean_score_COVID". The kurtosis (value $=1.78$; $\mathrm{SE}=0.20)$, skewness (value $=-1.21 ; \mathrm{SE}=0.10)$, Shapiro-Wilk test $(\mathrm{W}(622)=0.91 ; p<0.001)$, and histogram showed that the variable was not normally distributed [40]. Therefore, we calculated the Spearman correlation coefficient ( $r$ ) between the participants' scores on the COVID-19-SES and on the GSES [32,41,42]. A correlation coefficient $(r)$ higher than 0.3 was considered acceptable.

\section{Construct Validity}

To explore the COVID-19-SES' construct validity, we carried out an exploratory factor analysis (EFA) with principal axis factoring (PAF) and varimax rotation. Firstly, we computed the Kaiser-Mayer-Olkin test $(\mathrm{KMO})$ and Bartlett's test of sphericity to explore the adequacy of the analysis. A KMO $>0.7$ and a significant Bartlett's test $\left(\chi^{2}\right)$ were considered as indicators of the appropriateness to conduct an EFA [32,41,43]. The number of factors extracted as underlying dimensions of the COVID-19-SES was determined by: (1) the point where the curve of the scree plot clearly levelled off and (2) the number of factors with eigenvalues equal or higher than 1 [32,41,43]. Items were considered to be part of a factor (or dimension) when their factor-loading coefficient was $\geq 0.45$ [43].

\subsubsection{Reliability}

We explored the COVID-19-SES' reliability (i.e., internal consistency and test-retest reliability) following the same method as the one described in phase 1. Furthermore, we studied the correlations (Spearman's correlation coefficient) between the COVID-19-SES and all its sub-dimensions [32].

\subsubsection{Legibility}

We analysed the COVID-19-SES' legibility using the INFLESZ scale, which measures the difficulty of healthcare-related texts directed at laypeople [44]. According the INFLESZ scale, texts can be very easy (> 80), quite easy (66-80), normal (56-65), somewhat difficult (40-55), or very difficult $(<40)$ [44]. In addition, we included a text box in the online questionnaire for participants to express whether they had any difficulties reading, understanding, or completing the COVID-19-SES.

\subsubsection{Scoring and Interpretation System}

In order to facilitate the interpretation of the results yielded from the COVID-19-SES, we developed an internal scoring system following the experts' recommendations [32,38]. In this regard, we calculated the participants' mean score on the COVID-19-SES and its standard deviation (SD), which allowed us to create the following five scoring categories: (1) very low self-efficacy $=$ scores $>2$ SD below the mean, (2) low self-efficacy = scores between 1-2 SD below the mean, (3) moderate self-efficacy = scores $\leq 1 \mathrm{SD}$ below the mean, (4) high self-efficacy $=$ scores $\leq 1 \mathrm{SD}$ above the mean, and (5) very high self-efficacy $=$ scores $>1 \mathrm{SD}$ above the mean. 


\section{Results}

\subsection{Pilot Study Results}

Table 1 summarises the results of the pilot study. The experts considered that all the items were relevant to measure the intended construct (i-CVI > 0.78) and they were all kept as part of the COVID-19-SES that we administered to the pilot sample $(N=56)$. The COVID-19-SES' $\alpha$ was 0.905 and it would not have increased if we had removed any of the items. All the items' C-ITC was higher than 0.3 . Furthermore, the average measure ICC was 0.917 with a $95 \%$ confidence interval from 0.86 to $0.91(\mathrm{~F}(55,55)=12.00, p<0.001)$. All items were kept as part of the COVID-19-SES for its final validation study.

Table 1. Internal consistency and content validity results from the pilot study $(N=56)$.

\begin{tabular}{|c|c|c|c|c|}
\hline & & i-CVI ${ }^{1}$ & $\begin{array}{l}\text { NP-SES' Alpha if } \\
\text { Item Deleted }\end{array}$ & C-ITC ${ }^{2}$ \\
\hline Item 1. & $\begin{array}{l}\text { Regularly and thoroughly wash my hands with } \\
\text { soap and water or clean them with an alcohol-based } \\
\text { hand sanitiser wherever I go. }\end{array}$ & 1 & 0.906 & 0.316 \\
\hline Item 2. & $\begin{array}{l}\text { Cover my mouth and nose with a tissue or my bent } \\
\text { elbow every time I cough or sneeze. }\end{array}$ & 1 & 0.904 & 0.394 \\
\hline Item 3. & $\begin{array}{l}\text { Not touch my eyes, nose, or mouth under } \\
\text { any circumstances. }\end{array}$ & 0.93 & 0.903 & 0.475 \\
\hline Item 4. & $\begin{array}{l}\text { Maintain at least one metre distance between } \\
\text { myself and others at all time. }\end{array}$ & 0.93 & 0.903 & 0.459 \\
\hline Item 5. & $\begin{array}{l}\text { Avoid getting in contact with large groups of people } \\
\text { even if my professional and social life are at stake. }\end{array}$ & 1 & 0.902 & 0.490 \\
\hline Item 6. & $\begin{array}{l}\text { Only go outside when permitted and following the } \\
\text { government's directions. }\end{array}$ & 1 & 0.905 & 0.373 \\
\hline Item 7. & $\begin{array}{l}\text { Identify if I have symptoms of COVID-19 quickly } \\
\text { after they appear. }\end{array}$ & 0.93 & 0.899 & 0.657 \\
\hline Item 8. & $\begin{array}{l}\text { Decide when symptoms require me to either call } \\
\text { the COVID- } 19 \text { emergency phone number or go to } \\
\text { see a doctor, following the recommendations from } \\
\text { the health authorities. }\end{array}$ & 0.93 & 0.905 & 0.389 \\
\hline Item 9. & $\begin{array}{l}\text { Decide when my situation requires me to either call } \\
\text { the COVID-19 emergency phone number or } \\
\text { continue with my normal life, according to } \\
\text { recommendations from health authorities. }\end{array}$ & 0.86 & 0.903 & 0.466 \\
\hline Item 10. & $\begin{array}{l}\text { Call the correct phone number that the health } \\
\text { authorities of my region have enabled for } \\
\text { COVID-19 emergencies. }\end{array}$ & 1 & 0.902 & 0.505 \\
\hline Item 11. & $\begin{array}{l}\text { Isolate persons with symptoms in a well-ventilated } \\
\text { room for exclusive use, no matter how hard this } \\
\text { may be. }\end{array}$ & 0.86 & 0.901 & 0.537 \\
\hline Item 12. & $\begin{array}{l}\text { Ensure that the waste from the person with } \\
\text { symptoms goes into a self-closing rubbish bin with } \\
\text { a sealed bag, which is not shared with other } \\
\text { household members. }\end{array}$ & 0.93 & 0.898 & 0.644 \\
\hline Item 13. & $\begin{array}{l}\text { Reserve, if possible, a bathroom for the exclusive } \\
\text { use of the person with symptoms. }\end{array}$ & 0.79 & 0.907 & 0.461 \\
\hline Item 14. & $\begin{array}{l}\text { Keep the door to the room of the person with } \\
\text { symptoms closed at all times. }\end{array}$ & 0.93 & 0.896 & 0.703 \\
\hline
\end{tabular}


Table 1. Cont.

\begin{tabular}{llccc}
\hline & & i-CVI ${ }^{1}$ & $\begin{array}{c}\text { NP-SES' Alpha if } \\
\text { Item Deleted }\end{array}$ & C-ITC $^{2}$ \\
\hline Item 15. & $\begin{array}{l}\text { Limit the movement of the person with symptoms } \\
\text { in the house, even if it is sometimes difficult. }\end{array}$ & 0.93 & 0.892 & 0.828 \\
\hline Item 16. & $\begin{array}{l}\text { Maintain a minimum distance of } 1 \text { metre from the } \\
\text { person with symptoms at all times. }\end{array}$ & 0.86 & 0.894 & 0.753 \\
\hline Item 17. & $\begin{array}{l}\text { Ensure that the person with symptoms wears a } \\
\text { mask and gloves every time they leave the room, } \\
\text { without exception. }\end{array}$ & 0.79 & 0.898 & 0.798 \\
\hline $\begin{array}{l}\text { Carry out an exhaustive daily cleaning following } \\
\text { experts' recommendations regarding material, } \\
\text { disinfectant products, water temperature, and } \\
\text { important surfaces. }\end{array}$ & 1 & 0.896 \\
\hline $\begin{array}{l}\text { Remove the waste from the person with symptoms } \\
\text { following experts' safety recommendations. }\end{array}$ & 0.93 & 0.707 \\
\hline
\end{tabular}

\subsection{Participants and Descriptive Data}

Table 2 summarises the participants' characteristics. The participants' mean age was 35.80 $(\mathrm{SD}=13.89)$ and they were $68.8 \%$ female $(n=428)$. Almost $40 \%$ of the participants had completed primary or secondary education, $31 \%$ had completed vocational training, and around $30 \%$ had completed a university degree, masters or $\mathrm{PhD}$. In terms of participants' occupation, almost $25 \%$ were unemployed $(n=153)$ and $20 \%$ were healthcare professionals $(n=125)$. The majority of participants had not been diagnosed with a respiratory or cardiovascular chronic condition $(n=543)$ and had not experienced COVID-19 symptoms $(n=411)$. Most participants declared their health to be good $(n=352)$ or very good $(n=202)$. Tables 3 and 4 show the participants' mean score on each item and each sub-dimension of the COVID-19-SES.

Table 2. Participants' sociodemographic characteristics.

\begin{tabular}{lc}
\hline \multicolumn{1}{c}{ Characteristics } & Sample $(\mathbf{N}=\mathbf{6 2 2})$ \\
\cline { 2 - 2 } Age (years) & $\mathbf{M} \pm \mathbf{S D}$ \\
\hline Gender & $35.80 \pm 13.89$ \\
Female & \\
Male & $428(68.8)$ \\
\hline Highest educational level completed & $190(30.5)$ \\
Primary & \\
Secondary & $70(11.3)$ \\
Vocational qualification & $167(26.8)$ \\
University degree & $195(31.4)$ \\
Masters or PhD & $157(25.2)$ \\
\hline Occupation & $33(5.3)$ \\
Unemployed & \\
Healthcare professional & $153(24.6)$ \\
Qualified worker & $125(20.1)$ \\
Non-qualified worker & $222(35.7)$ \\
Retired & $111(17.8)$ \\
\hline Have you experienced COVID-19 symptoms? & $11(1.8)$ \\
Yes & \\
No & $18(2.9)$ \\
I am not sure & $411(66.1)$ \\
\hline
\end{tabular}


Table 2. Cont.

\begin{tabular}{lc}
\hline \multicolumn{1}{c}{ Characteristics } & Sample $(\boldsymbol{N}=\mathbf{6 2 2})$ \\
\cline { 2 - 2 } & $\mathbf{M} \pm \mathbf{S D}$ \\
\hline Respiratory or cardiovascular chronic condition & $79(12.7)$ \\
Yes & $543(87.3)$ \\
No & \\
\hline Perceived general health & $1(0.2)$ \\
$\quad$ Very poor & $5(0.8)$ \\
Poor & $62(10.0)$ \\
Normal & $352(56.6)$ \\
Good & $202(32.5)$ \\
Very good &
\end{tabular}

Table 3. Internal consistency and content validity results from the final validation study $(N=622)$.

\begin{tabular}{|c|c|c|c|c|c|}
\hline & & i-CVI & $\begin{array}{l}\text { NP-SES' Alpha if } \\
\text { Item Deleted }\end{array}$ & C-ITC & $\mathrm{M} \pm \mathrm{SD}$ \\
\hline Item 1. & Regularly and thoroughly wash my [ ... ]. & 1 & 0.906 & 0.364 & $88.90 \pm 17.15$ \\
\hline Item 2. & Cover my mouth and nose with a $[\ldots]$. & 1 & 0.905 & 0.448 & $92.30 \pm 14.15$ \\
\hline Item 3. & Not touch my eyes, nose or mouth $[\ldots]$. & 0.93 & 0.905 & 0.425 & $68.30 \pm 24.85$ \\
\hline Item 4. & Maintain at least one metre $[\ldots]$ & 0.93 & 0.906 & 0.397 & $79.70 \pm 22.55$ \\
\hline Item 5. & Avoid getting in contact with large $[\ldots]$. & 1 & 0.907 & 0.329 & $90.30 \pm 17.94$ \\
\hline Item 6. & Only go outside when permitted [ ... ]. & 1 & 0.905 & 0.423 & $94.00 \pm 14.12$ \\
\hline Item 7. & Identify if I have symptoms [ . . . ]. & 0.93 & 0.904 & 0.459 & $79.60 \pm 20.99$ \\
\hline Item 8. & Decide when symptoms require $[\ldots]$. & 0.93 & 0.904 & 0.480 & $84.10 \pm 20.49$ \\
\hline Item 9. & Decide when my situation requires $[\ldots]$ & 0.86 & 0.903 & 0.513 & $84.40 \pm 19.66$ \\
\hline Item 10. & Call the correct phone number $[\ldots]$ & 1 & 0.904 & 0.477 & $89.20 \pm 18.23$ \\
\hline Item 11. & Isolate the person with symptoms $[\ldots]$ & 0.86 & 0.896 & 0.744 & $82.20 \pm 24.73$ \\
\hline Item 12. & Ensure that the waste from the $[\ldots]$. & 0.93 & 0.897 & 0.701 & $77.90 \pm 28.03$ \\
\hline Item 13. & Reserve, if possible, a bathroom [ ... ]. & 0.79 & 0.908 & 0.464 & $72.10 \pm 37.32$ \\
\hline Item 14. & Keep the door to the room of the $[\ldots]$. & 0.93 & 0.897 & 0.718 & $81.10 \pm 27.63$ \\
\hline Item 15. & Limit the movement of the person $[\ldots]$ & 0.93 & 0.895 & 0.778 & $81.70 \pm 25.46$ \\
\hline Item 16. & Maintain a minimum distance $[\ldots]$. & 0.86 & 0.897 & 0.719 & $79.90 \pm 26.44$ \\
\hline Item 17. & Ensure that the person with $[\ldots]$ & 0.79 & 0.900 & 0.626 & $81.50 \pm 27.77$ \\
\hline Item 18. & Carry out an exhaustive daily $[\ldots]$. & 1 & 0.897 & 0.741 & $82.90 \pm 23.12$ \\
\hline Item 19. & Remove the waste from the person $[\ldots]$ & 0.93 & 0.896 & 0.743 & $81.40 \pm 24.40$ \\
\hline
\end{tabular}

$\mathrm{i}$-CVI = Content Validity Index of each item; C-ITC = Corrected Item-Total Correlation; $\mathrm{M}=\mathrm{Mean}$; $\mathrm{SD}=$ Standard Deviation.

Table 4. Exploratory factor analysis results and structure of the COVID-19-SES $(N=622)$.

\begin{tabular}{lccc}
\hline & \multicolumn{3}{c}{ FACTOR } \\
\cline { 2 - 4 } & $\mathbf{1}$ & $\mathbf{2}$ & $\mathbf{3}$ \\
\hline \multicolumn{2}{l}{ Prevention of COVID-19 contagion and spread } \\
\hline Item 1 & 0.090 & 0.172 & $\mathbf{0 . 5 3 3}$ \\
Item 2 & 0.189 & 0.138 & $\mathbf{0 . 5 6 9}$ \\
Item 3 & 0.185 & 0.164 & $\mathbf{0 . 5 1 8}$ \\
Item 4 & 0.191 & 0.058 & $\mathbf{0 . 5 3 1}$ \\
Item 5 & 0.093 & 0.020 & $\mathbf{0 . 5 9 4}$ \\
Item 6 & 0.208 & 0.180 & $\mathbf{0 . 4 5 1}$ \\
\hline
\end{tabular}


Table 4. Cont.

\begin{tabular}{lccc}
\hline & \multicolumn{3}{c}{ FACTOR } \\
\cline { 2 - 4 } & $\mathbf{1}$ & $\mathbf{2}$ & $\mathbf{3}$ \\
\hline \multicolumn{3}{l}{ Recognition of COVID-19 symptoms } \\
\hline Item 7 & 0.183 & $\mathbf{0 . 6 4 8}$ & 0.167 \\
Item 8 & 0.133 & $\mathbf{0 . 8 9 1}$ & 0.143 \\
Item 9 & 0.188 & $\mathbf{0 . 8 4 2}$ & 0.144 \\
Item 10 & 0.231 & $\mathbf{0 . 5 4 3}$ & 0.208 \\
\hline Home-management of people with COVID-19 symptoms \\
\hline Item 11 & $\mathbf{0 . 8 0 3}$ & 0.160 & \\
Item 12 & $\mathbf{0 . 7 0 4}$ & 0.146 & 0.193 \\
Item 13 & $\mathbf{0 . 5 5 5}$ & 0.076 & 0.057 \\
Item 14 & $\mathbf{0 . 8 0 3}$ & 0.157 & 0.136 \\
Item 15 & $\mathbf{0 . 8 7 3}$ & 0.158 & 0.162 \\
Item 16 & $\mathbf{0 . 7 5 7}$ & 0.133 & 0.228 \\
Item 17 & $\mathbf{0 . 6 2 2}$ & 0.171 & 0.222 \\
Item 18 & $\mathbf{0 . 6 4 4}$ & 0.249 & 0.358 \\
Item 19 & $\mathbf{0 . 6 7 9}$ & 0.231 & 0.324 \\
\hline$\%$ of variance & 26.31 & 13.66 & 12.15 \\
\% of cumulative variance & 26.31 & 39.97 & 52.12 \\
\hline
\end{tabular}

The factor loading figures in bold indicate which factor each item loads onto.

\subsection{Validity}

Content validity analysis showed that all the items' i-CVI $>0.78$ (See Table 3) and the COVID-19-SES' S-CVI was 0.92 . In terms of criterion validity, our analysis indicated that the participants' scores on the COVID-19-SES moderately correlated with their scores on the GSES $(\mathrm{r}=0.38 ; p<0.001)$. Regarding the COVID-19-SES' construct validity, the KMO test $(\mathrm{KMO}=0.904)$ and the Bartlett's test of sphericity $\left(\chi^{2}(171)=6585.145 ; p<0.001\right)$ evidenced the appropriateness for an EFA to be conducted. Our PAF analysis showed that the COVID-19-SES has three underlying factors that explained $52.12 \%$ of the cumulative variance found (see Table 4). These three factors presented an eigenvalue $>1$ and all the items loaded onto one factor with a factor-loading coefficient $>0.45$. Table 4 shows the COVID-19-SES' dimensional structure: [Factor 1] prevention of COVID-19 contagion and spread, [Factor 2] recognition of COVID-19 symptoms, and [Factor 3] home-management of people with COVID-19 symptoms.

\subsection{Reliability}

Table 3 presents the items' C-ITC and the scale's $\alpha$ if the items were removed. The COVID-19-SES' $\alpha$ was 0.906 , all the items' C-ITC $>0.3$, and the scale's $\alpha$ would not have increased if we had removed any of the items. Additionally, all the sub-dimensions' $\alpha$ was higher than 0.70 (see Table 5). Regarding test-retest reliability, $85 \%$ of participants completed the retest after 4 weeks $(n=531)$ and we found that the average measure ICC was 0.757 with a $95 \%$ confidence interval from 0.71 to $0.80(\mathrm{~F}(530,530)=4.12$, $p<0.001)$. Lastly, Table 6 shows that all the correlations between the participants' mean total score for the COVID-SES-19 and its sub-dimensions were higher than 0.30 .

Table 5. Cronbach's alpha and descriptive data for the COVID-19-SES and its sub-dimensions.

\begin{tabular}{ccc}
\hline & Cronbach's Alpha & M \pm SD \\
\hline COVID-19-SES & 0.905 & $83.32 \pm 13.24$ \\
Prevention of COVID-19 contagion and spread & 0.726 & $85.58 \pm 12.27$ \\
Recognition of COVID-19 symptoms & 0.852 & $84.31 \pm 16.54$ \\
Home-management of people with COVID-19 symptoms & 0.919 & $80.09 \pm 13.24$ \\
\hline
\end{tabular}

$\mathrm{M}=$ Mean; $\mathrm{SD}=$ Standard Deviation. 
Table 6. Correlations between COVID-19-SES and its sub-dimensions.

\begin{tabular}{cccc}
\hline & Prevention & Recognition & Home-Management \\
\hline Prevention & - & - & - \\
Recognition & $0.389^{*}$ & - & - \\
Home-management & $0.491^{*}$ & $0.444^{*}$ & - \\
Total COVID-19-SES & $0.721^{*}$ & $0.746^{*}$ & $0.849 *$ \\
\hline \multicolumn{4}{c}{ * significant at the 0.01 level (2-tailed). }
\end{tabular}

* significant at the 0.01 level (2-tailed).

\subsection{Legibility}

The results from the INFLESZ analysis (score $=68.04$ ) showed that the COVID-19-SES was "quite easy" to read and understand by laypeople. Furthermore, none of the participants reported any difficulties to read, understand, or complete the scale.

\subsection{Scoring and Interpretation System}

The participants' mean score on the COVID-19-SES was $83.32(\mathrm{SD}=13.24)$. We developed the following internal scoring system: (1) very low self-efficacy $=$ scores below $55,(2)$ low self-efficacy $=$ scores 55-68, (3) moderate self-efficacy = scores 69-82, (4) high self-efficacy $=$ scores 83-96, and (5) very high self-efficacy $=$ scores above 96 .

\section{Discussion}

The aim of this study was to develop and psychometrically test the COVID-19 prevention, recognition, and home-management self-efficacy scale (COVID-19-SES). Bandura's theoretical framework suggests that higher levels of self-efficacy indicate individuals' higher motivation towards carrying out a given task $[25,26]$. In fact, self-efficacy has been linked to better preventive behavioural responses in a pandemic outbreak [24,27-29]. In an attempt to control the pandemic, many governments have urged the general public to confine themselves at home and/or to adopt protective behaviours that can alter their day-to-day life $[10,12,18,19]$. Developing an instrument for the assessment of individuals' self-efficacy to adopt preventive measures would allow healthcare professionals to explore the general public's behavioural responses amidst the public health emergency generated by the COVID-19 pandemic [19].

When a psychometric instrument is developed, we have to carefully examine its validity and reliability [32,34]. Whilst validity refers to the instrument's ability to actually measure the construct that it intends to measure $[33,41]$, reliability refers to its ability to produce accurate and consistent results across time [32,33]. In this study, we assessed the COVID-19-SES' validity and reliability. Furthermore, we analysed its legibility and created a scoring system to facilitate the interpretation of the results $[32,38]$.

Regarding the COVID-19-SES' validity, we analysed its content, criterion, and construct validity [34]. A panel of 14 independent experts critically reviewed the COVID-19-SES and decided that all the items comprising the tool were relevant to measure individuals' self-efficacy in preventing, recognising symptoms and home-managing COVID-19 [41]. In terms of criterion validity, our analysis showed that the participants' results on the COVID-19-SES moderately correlated to their results on the general self-efficacy scale. Self-efficacy is situation-specific and people can be more or less efficacious in some realms than others $[25,45]$. Although both instruments assess people's self-efficacy, they both refer to very different realms in their lives and this could explain why we found a moderate correlation between them. With regard to our construct validity analysis, we found that the COVID-19-SES has a three-dimension structure. The three dimensions of the COVID-19-SES allow for the assessment of people's self-efficacy in preventing the contagion and spread of COVID-19, recognising COVID-19 symptoms, and home-managing patients with mild COVID-19 symptoms. These three dimensions are in line with the WHO's recommendations for the general public to avoid the contagion and spread of COVID-19 [11,20]. In general, the results from our validity analysis suggest that the COVID-19-SES is 
a valid instrument for assessing the general public's self-efficacy in their ability to adopt preventive behaviours to prevent, recognise symptoms, and home-manage COVID-19 [32,33,41]. In terms of reliability, our analysis has shown that all the items of the COVID-19-SES contribute to its strong internal consistency. Additionally, our test-retest reliability analysis suggests that the COVID-19-SES can yield consistent results across time. This evidence indicates that the COVID-19-SES can measure the general public's self-efficacy in preventing, recognising symptoms, and home-managing COVID-19 in a reliable and consistent manner $[32,33,41]$. Contributing to the good psychometric properties of the tested instrument, our legibility analysis showed that the COVID-19-SES is easy to read, understand, and complete by laypeople [44]. Lastly, our descriptive analysis showed that our participants are highly efficacious in preventing, recognising symptoms, and home-managing COVID-19. This could be related to the fact that the Spanish government has implemented strict measures to oblige the general public to implement protective measures against the contagion and spread of COVID-19 [19]. Future research should use the COVID-19-SES to collect data about different populations' self-efficacy in order to deepen our understanding of its mediating effect on people's behavioural responses to the pandemic over time.

Although we conducted a methodologically rigorous study, we need to highlight some limitations. Firstly, our sample was selected through a convenience sampling technique, which means that our results cannot be generalised. Although participants stated they were from 33 different provinces in Spain, we suggest that future studies use a stratified sampling method to recruit a representative sample. Secondly, our sample mainly comprised of young, healthy adults. It is important to test the COVID-19-SES' main psychometric properties amongst samples of people with specific clinical, social, or behavioural backgrounds. Thirdly, the COVID-19-SES was developed and validated in Spanish. Although the instrument complies with the WHO's recommendations to prevent the contagion and spread of COVID-19, its use in a different language should be preceded by a psychometric evaluation. Fourthly, due to the strict lockdown measures implemented by the Spanish government during the COVID-19 outbreak, we could only collect data through online surveying. Populations with limited access to the Internet or social media may be unrepresented. Lastly, data were collected through self-administered questionnaires. Since the Spanish government decreed the state of alarm and people were obliged to comply with some of the preventive behaviours reflected in the COVID-19-SES [12], the study participants could have fallen into social desirability bias.

\section{Conclusions}

Following an exhaustive assessment, the COVID-19-SES has shown to have good psychometric properties. Our results suggest that the COVID-19-SES is a valid, reliable, and legible instrument that would allow for the assessment of people's self-efficacy in preventing, recognising symptoms, and home-managing COVID-19. Healthcare professionals and behavioural scientists should use the COVID-19-SES to study both people's level of confidence in their ability to adopt protective behaviours amidst future waves of the pandemic as well as the relationship between self-efficacy and people's behavioural responses in a pandemic caused by an infectious respiratory disease. The results yielded from the COVID-19-SES could provide information about people's motivation to comply with the recommended protective behaviours. Therefore, healthcare professionals could use the COVID-19-SES when they require patients with (or suspected) mild COVID-19 symptoms and relatives to isolate themselves at home. Low levels of self-efficacy in preventing, recognising symptoms, and home-managing COVID-19 could indicate the need for health education interventions. Future studies should focus on testing the COVID-19-SES amongst different populations in different socio-cultural contexts and confirming the tool's dimensionality.

Author Contributions: Conceptualization, J.M.H.-P., J.G.-M., and C.F.-S.; methodology, J.M.H.-P., J.G.M., C.F.-S., and M.M.L.-R.; data curation, M.D.R.-F., I.D.-S., I.M.F.-M, M.M.L.-R., and M.C.-C.; formal analysis, J.M.H.-P., M.D.R.-F., I.D.-S., I.M.F.-M., and M.M.L.-R.; writing—original draft preparation, J.M.H.-P., I.D.-S., and M.C.-C.; 
writing-review and editing, J.M.H.-P., J.G.-M., C.F.-S., M.D.R.-F., I.D.-S., I.M.F.-M., M.M.L.-R., and M.C.-C. All authors have read and agreed to the published version of the manuscript.

Funding: This research received funding from the CTS-451 "Health Sciences" Research Group and the Health Research Centre (CEINSA) from the Universidad de Almería.

Acknowledgments: The authors would like to thank all the participants and independent experts for volunteering to take part in this study. We also thank the CTS-451 "Health Sciences" Research Group and the Health Research Centre (CEINSA) from the University of Almería for their financial support.

Conflicts of Interest: The authors declare no conflict of interest.

\section{References}

1. Jiang, F.; Deng, L.; Zhang, L.; Cai, Y.; Cheung, C.W.; Xia, Z. Review of the clinical characteristics of coronavirus disease 2019 (COVID-19). J. Gen. Intern. Med. 2020, 35, 1545-1549. [CrossRef]

2. Rothan, H.A.; Byrareddy, S.N. The epidemiology and pathogenesis of coronavirus disease (COVID-19) outbreak. J. Autoimmun. 2020, 109, 102433. [CrossRef]

3. Zhou, F.; Yu, T.; Du, R.; Fan, G.; Liu, Y.; Liu, Z.; Xiang, J.; Wang, Y.; Song, B.; Gu, X.; et al. Clinical course and risk factors for mortality of adult inpatients with COVID-19 in Wuhan, China: A retrospective cohort study. Lancet 2020, 395, 1054-1062. [CrossRef]

4. Day, M. Covid-19: Four fifths of cases are asymptomatic, China figures indicate. BMJ 2020, 369, m1375. [CrossRef] [PubMed]

5. Wu, Z.; McGoogan, J.M. Characteristics of and important lessons from the coronavirus disease 2019 (COVID-19) outbreak in China: Summary of a report of 72,314 cases from the Chinese Center for Disease Control and Prevention. JAMA 2020, 323, 1239-1242. [CrossRef] [PubMed]

6. Weiss, P.; Murdoch, D.R. Clinical course and mortality risk of severe COVID-19. Lancet 2020, 395, 1014-1015. [CrossRef]

7. Grasselli, G.; Pesenti, A.; Cecconi, M. Critical care utilization for the COVID-19 outbreak in Lombardy, Italy: Early experience and forecast during an emergency response. JAMA 2020, 323, 1545-1546. [CrossRef]

8. Livingston, E.; Bucher, K. Coronavirus disease 2019 (COVID-19) in Italy. JAMA 2020, 323, 1335. [CrossRef]

9. Wang, D.; Hu, B.; Hu, C.; Zhu, F.; Liu, X.; Zhang, J.; Wang, B.; Xiang, H.; Cheng, Z.; Xiong, Y.; et al. Clinical characteristics of 138 hospitalized patients with 2019 novel coronavirus-infected pneumonia in Wuhan, China. JAMA 2020, 323, 1061-1069. [CrossRef]

10. Steffens, I. A hundred days into the coronavirus disease (COVID-19) pandemic. Eurosurveillance 2020, 5, 2000550. [CrossRef]

11. World Health Organisation (WHO). Coronavirus Disease (COVID-19) Advice for the Public. Available online: https://www.who.int/emergencies/diseases/novel-coronavirus-2019/advice-for-public (accessed on 29 April 2020).

12. Soriano-Maldonado, A.; Checa-Olmos, J.C.; Castillo-Garzón, M.J. Loosening restrictions in Spain: Testing, immunization, and idiosyncrasy. BMJ 2020, 369, m1918. [CrossRef]

13. Leung, K.; Wu, J.T.; Liu, D.; Leung, G.M. First-wave COVID-19 transmissibility and severity in China outside Hubei after control measures, and second-wave scenario planning: A modelling impact assessment. Lancet 2020, 395, 1382-1393. [CrossRef]

14. Liu, Y.; Gayle, A.A.; Wilder-Smith, A.; Rocklöv, J. The reproductive number of COVID-19 is higher compared to SARS coronavirus. J. Travel Med. 2020, 27, 1-4. [CrossRef] [PubMed]

15. Yuan, J.; Li, M.; Lv, G.; Lu, Z.K. Monitoring transmissibility and mortality of COVID-19 in Europe. Int. J. Infect. Dis. 2020, 95, 311-315. [CrossRef] [PubMed]

16. Ferguson, N.M.; Laydon, D.; Nedjati-Gilani, G.; Imai, N.; Ainslie, K.; Baguelin, M.; Bhatia, S.; Boonyasiri, A.; Cucunubá, Z.; Cuomo-Dannenburg, G.; et al. Impact of Non-Pharmaceutical Interventions (NPIs) to Reduce COVID-19 Mortality and Healthcare Demand. Imperial College COVID-19 Response Team: London, UK, 2020. Available online: https://www.imperial.ac.uk/media/imperial-college/medicine/sph/ide/gidafellowships/Imperial-College-COVID19-NPI-modelling-16-03-2020.pdf (accessed on 29 April 2020).

17. Li, R.; Rivers, C.; Tan, Q.; Murray, M.B.; Toner, E.; Lipsitch, M. Estimated demand for US hospital inpatient and intensive care unit beds for patients with COVID-19 based on comparisons with Wuhan and Guangzhou, China. JAMA Netw. Open 2020, 3, e208297. [CrossRef] 
18. Lazzerini, M.; Putoto, G. COVID-19 in Italy: Momentous decisions and many uncertainties. Lancet Glob. Health 2020, 8, e641-e642. [CrossRef]

19. Legido-Quigley, H.; Mateos-García, J.T.; Campos, V.R.; Gea-Sánchez, M.; Muntaner, C.; McKee, M. The resilience of the Spanish health system against the COVID-19 pandemic. Lancet Public Health 2020, 5 , e251-e252. [CrossRef]

20. World Health Organisation (WHO). Home Care for Patients with COVID-19 Presenting with Mild Symptoms and Management of Their Contacts. Available online: https://www.who.int/publications-detail/home-carefor-patients-with-suspected-novel-coronavirus-(ncov)-infection-presenting-with-mild-symptoms-andmanagement-of-contacts (accessed on 29 April 2020).

21. Di Gennaro, F.; Pizzol, D.; Marotta, C.; Antunes, M.; Racalbuto, V.; Veronese, N.; Smith, L. Coronavirus diseases (COVID-19) current status and future perspectives: A narrative review. Int. J. Environ. Res. Public Health 2020, 17, 2690. [CrossRef] [PubMed]

22. Kissler, S.M.; Tedijanto, C.; Goldstein, E.; Grad, Y.H.; Lipsitch, M. Projecting the transmission dynamics of SARS-CoV-2 through the postpandemic period. Science 2020, eabb5793. [CrossRef]

23. Sheeran, P.; Maki, A.; Montanaro, E.; Avishai-Yitshak, A.; Bryan, A.; Klein, W.M.; Miles, E.; Rothman, A.J. The impact of changing attitudes, norms, and self-efficacy on health-related intentions and behavior: A meta-analysis. Health Psychol. 2016, 35, 1178-1188. [CrossRef]

24. Williams, L.; Rasmussen, S.; Kleczkowski, A.; Maharaj, S.; Cairns, N. Protection motivation theory and social distancing behaviour in response to a simulated infectious disease epidemic. Psychol. Health Med. 2015, 20, 832-837. [CrossRef] [PubMed]

25. Bandura, A. Self-efficacy beliefs of adolescents. In Adolescence and Education; Pajares, F., Urdan, T., Eds.; Information Age Publishing: Greenwich, UK, 2006; pp. 307-337.

26. Williams, D.M.; Rhodes, R.E. The confounded self-efficacy construct: Conceptual analysis and recommendations for future research. Health Psychol. Rev. 2016, 10, 113-128. [CrossRef] [PubMed]

27. Bults, M.; Beaujean, D.J.; de Zwart, O.; Kok, G.; van Empelen, P.; van Steenbergen, J.E.; Richardus, J.H.; Voeten, H.A. Perceived risk, anxiety, and behavioural responses of the general public during the early phase of the Influenza A (H1N1) pandemic in the Netherlands: Results of three consecutive online surveys. BMC Public Health 2011, 11, 2. [CrossRef] [PubMed]

28. Lau, J.T.; Griffiths, S.; Au, D.W.; Choi, K.C. Changes in knowledge, perceptions, preventive behaviours and psychological responses in the pre-community outbreak phase of the H1N1 epidemic. Epidemiol. Infect. 2011, 139, 80-90. [CrossRef] [PubMed]

29. Tang, C.S.; Wong, C.Y. An outbreak of the severe acute respiratory syndrome: Predictors of health behaviors and effect of community prevention measures in Hong Kong, China. Am. J. Public Health 2003, 93, 1887-1888. [CrossRef]

30. Lau, J.T.; Griffiths, S.; Choi, K.C.; Lin, C. Prevalence of preventive behaviors and associated factors during early phase of the H1N1 influenza epidemic. Am. J. Infect. Control 2010, 38, 374-380. [CrossRef]

31. Wong, T.W.; Tam, W.W. Handwashing practice and the use of personal protective equipment among medical students after the SARS epidemic in Hong Kong. Am. J. Infect. Control 2005, 33, 580-586. [CrossRef]

32. Polit, D.; Beck, C.T. Nursing Research: Generating and Assessing Evidence for Nursing Practice, 11th ed.; Wolters Kluwer: Philadelphia, PA, USA, 2020.

33. Norman, G.R.; Streiner, D.L. Biostatistics: The Bare Essentials, 3rd ed.; B.C. Decker: Hamilton, ON, Canada, 2014.

34. Streiner, D.L.; Kottner, J. Recommendations for reporting the results of studies of instrument and scale development and testing. J. Adv. Nurs. 2014, 70, 1970-1979. [CrossRef]

35. Herrero, R.; Espinoza, M.; Molinari, G.; Etchemendy, E.; Garcia-Palacios, A.; Botella, C.; Baños, R.M. Psychometric properties of the general self efficacy-12 scale in Spanish: General and clinical population samples. Compr. Psychiatry 2014, 55, 1738-1743. [CrossRef]

36. Hernández-Padilla, J.M.; Cortés-Rodríguez, A.E.; Granero-Molina, J.; Fernández-Sola, C.; Correa-Casado, M.; Fernández-Medina, I.M.; López-Rodríguez, M.M. Design and psychometric evaluation of the 'clinical communication self-efficacy toolkit'. Int. J. Environ. Res. Public Health 2019, 16, 4534. [CrossRef]

37. Hessling, R.; Traxel, N.; Schmidt, T. Ceiling effect. In The SAGE Encyclopedia of Social Science Research Methods, 1st ed.; Lewis-Beck, M.S., Bryman, A., Liao, T.F., Eds.; SAGE Publications, Inc.: Thousand Oaks, CA, USA, 2004. 
38. Brestoff, J.R.; Van den Broeck, J. Reporting data quality. In Epidemiology: Principles and Practical Guidelines, 1st ed.; Brestoff, J.R., Van den Broeck, J., Eds.; Springer: Dordrecht, The Netherlands, 2013; pp. 557-570.

39. Epstein, J.; Santo, R.M.; Guillemin, F. A review of guidelines for cross-cultural adaptation of questionnaires could not bring out a consensus. J. Clin. Epidemiol. 2015, 68, 435-441. [CrossRef] [PubMed]

40. George, D.; Mallery, P. IBM SPSS Statistics 23 Step by Step, 14th ed.; Routledge: New York, NY, USA, 2016.

41. Coaley, K. An Introduction to Psychological Assessment and Psychometrics, 2nd ed.; SAGE Publications: London, UK, 2014.

42. Hernández-Padilla, J.M.; Granero-Molina, J.; Márquez-Hernández, V.V.; Suthers, F.; Fernández-Sola, C. Development and psychometric evaluation of the arterial puncture self-efficacy scale. Nurse Educ. Today 2016, 40, 45-51. [CrossRef] [PubMed]

43. Tabachnick, B.; Fidell, L. Using Multivariate Statistics, 7th ed.; Pearson: Essex, UK, 2019.

44. Barrio-Cantalejo, I.; Simón-Lorda, P.; Melguizo, M.; Escalona, I.; Marijuán, M.; Hernando, P. Validation of the INFLESZ scale to evaluate readability of texts aimed at the patient. An. Sist. Sanit. Navar. 2008, 31, $135-152$. [CrossRef]

45. Schutte, N.S.; Malouff, J.M. General and Realm-Specific Self-Efficacy: Connections to Life Functioning. Curr. Psychol. 2016, 361-369. [CrossRef]

(C) 2020 by the authors. Licensee MDPI, Basel, Switzerland. This article is an open access article distributed under the terms and conditions of the Creative Commons Attribution (CC BY) license (http://creativecommons.org/licenses/by/4.0/). 